\title{
La crítica de Averroes contra el determinismo de al-Ghazālī y los asharíes*
}

\author{
LUIS XAVIER LÓPEZ FARJEAT \\ Facultad de Filosofía \\ Universidad Panamericana \\ llopez@up.edu.mx
}

\begin{abstract}
Resumen: El objetivo de este trabajo es discutir la "doctrina kasb" o "doctrina de la adquisición", formulada por uno de los sectores teológicos más importantes del Islam, i.e., los asharíes. Dicha doctrina plantea una cuestión compleja: ¿quién es el verdadero agente de las acciones humanas? ¿Es el ser humano o Dios? El asharí más renombrado que intenta resolver estas cuestiones es al-Ghazālī. Después de explicar cuán problemática es la doctrina de la adquisición, analizaré los argumentos de Averroes en la Inconsistencia de la inconsistencia, con la finalidad de encontrar si verdaderamente refutan el determinismo asharí.
\end{abstract}

Palabras clave: filosofía árabe-islámica, teología asharí, determinismo islámico, al-Ghazālī, Averroes

\begin{abstract}
The aim of this paper is to discuss the kasb doctrine, or "acquisition doctrine", formulated by one of the most important Islamic theological sectors, i.e., the Asharites. This doctrine raises a complex question: Who is the actual agent of human actions? Is it human beings or is it God? The most renowned Asharite who tried to solve these questions is al-Ghazālì. After explaining how problematic the acquisition doctrine is, I will analyze Averroes' arguments in the Incoherence of the Incoherence in order to find out if they really refute the Asharite determinism.
\end{abstract}

Key words: Arabic/Islamic philosophy, Asharite theology, Islamic determinism, al-Ghazālī, Averroes

En el Corán se postula, presuntamente, cierta clase de determinismo divino. Por ejemplo, un pasaje significativo y frecuentemente aludido por los teólogos asharíes es el siguiente: "Allāh os ha creado a vosotros y a lo que hacéis" (Corán 37:96). No es sencillo interpretar el sentido preciso de estas palabras: ¿significan, acaso, que nuestras acciones provienen de Dios? A este respecto, en el propio Corán hay pasajes contradictorios: por una parte, en algunos lugares se afirma que el ser humano es responsable de sus acciones $(16: 96 ; 21: 23 ; 18: 29-30 ; 32: 14)$; no obstante, en otros se confirma la omnipotencia divina y se alude a la predeterminación de todo cuanto ocurre en el mundo (39:63, 37:94-96, 67:

*Este trabajo fue elaborado en el marco de actividades del proyecto CONACYT 49596. Agradezco a los dictaminadores anónimos sus observaciones, pues fueron de gran ayuda. 
13-14). Los teólogos y filósofos musulmanes trataron de resolver estas presuntas contradicciones ofreciendo distintas interpretaciones de los versos coránicos. ${ }^{1}$

Una de las escuelas teológicas más representativas fue la de los asharíes. Su fundador, al-Ash arī (873-935), es una de las figuras centrales del sector musulmán sunnita, el más numeroso en nuestros días. Es propiamente un teólogo, aunque sus obras tocan una serie de problemáticas filosóficas que van desde la creación del mundo hasta el conflicto entre la omnipotencia divina y la libertad humana. A este último respecto, los asharíes formularon una doctrina denominada kasb o de la "adquisición", que plantea una interrogante compleja: ¿quién es el verdadero agente de los acontecimientos y acciones que se suscitan en el mundo? El asharí más renombrado que intenta resolver esta cuestión es al-Ghazālī (1058-1111). ${ }^{2}$ Después de explicar en qué consiste la doctrina $k a s b$, revisaré la versión que de ella presenta al-Ghazālī en las discusiones tercera y decimoséptima de su obra titulada Tahāfut al-falāsifa (La incoherencia de los filósofos). Finalmente, discutiré los argumentos de Averroes en contra de al-Ghazālī y los asharíes. Se trata de someterlos a prueba para evaluar si resultan lo suficientemente efectivos para desarmar el determinismo tal como, según Averroes, está planteado en los asharíes.

${ }^{1}$ Un trabajo ilustrativo a este respecto es el de Abdur Rashid Bhat (2006). El autor mantiene una interpretación ligeramente distinta de la mía, pues tal parece que, desde su punto de vista, al-Ghazālī no es un determinista. Lo más valioso de su artículo es la última parte, dedicada a la discusión de esta misma temática en pensadores islámicos de finales del siglo XIX y la primera mitad del XX, tales como Muhammad Iqbal, M. Pickthal, Sayyid Abdul Ala Maududi y Fazlur Rahman, entre otros.

${ }^{2}$ Aunque me refiero a al-Ghazālī como un teólogo asharí, en realidad es un pensador que difícilmente puede encasillarse en una vertiente específica. R.M. Frank (1994) ha dedicado un libro entero al estudio de la relación entre al-Ghazālī y los asharíes. Aunque no hay duda alguna de su cercanía a esta escuela, su trayectoria intelectual es de lo más variada. De ahí que aunque en varias de sus obras simpatiza con los asharíes, en otras más es crítico de la metodología de los teólogos en general y adopta la argumentación filosófica; sin embargo, utiliza dicha argumentación para mostrar las inconsistencias de los argumentos metafísicos de los filósofos musulmanes. Hacia el final de su vida, al-Ghazālī simpatizó con el misticismo de los sufíes. En su autobiografía intelectual titulada al-Munqidh min al-dalal (El salvador del error) (1989), relata en un tono similar al de las Confesiones de san Agustín su encuentro con la teología, con la filosofía y con el sufismo. 


\section{El planteamiento asharí y la discusión decimoséptima del Tahāfut de al-Ghazā $\bar{\imath}$}

Una de las discusiones más conocidas en la filosofía árabe-islámica medieval es la que intenta responder qué es lo que debe interpretarse cuando el Corán se refiere a Dios como Creador y agente del mundo ${ }^{3}$. Filósofos y teólogos suelen interpretar esta tesis de manera distinta. Las discrepancias a este respecto son el origen de una serie de discusiones en las que los asharíes desempeñan un papel protagónico. Éstos interpretan que, si Dios es agente del mundo, entonces todo cuanto acontece en él proviene de la voluntad divina. Escribe Ash arī:

la voluntad, siendo uno de los atributos de la Esencia [divina] tal y como hemos mostrado, debe abarcar todo aquello que puede realmente quererse, así como el conocimiento, siendo uno de los atributos de la Esencia

${ }^{3}$ De hecho, ésta es la primera cuestión que se "demuestra" en el Kitāb al-Luma" [Contra heterodoxos] de al-Ash arī. Ahí, la prueba (dalīl) que confirma que este mundo creado tiene un Hacedor (şānic) y un Dirigente (mudabbir), es la siguiente: "La prueba es que el hombre maduro fue en su origen semen, luego embrión, después feto, y finalmente carne, hueso[s] y sangre. Pues sabemos que él no se trasladó [entonces voluntariamente] de un estado a otro, dado que cuando su estado es física y mentalmente pleno [o maduro] él es incapaz, por sí mismo, de devenir [v.gr.] oyente y vidente, o de crear por sí mismo una mano u otro miembro físico; luego, cuando su estado era más débil e imperfecto tampoco pudo él hacer nada de eso, pues si [el hombre] puede hacer algo cuando su estado es [inmaduro e] imperfecto, puede hacerlo también cuando su estado es [maduro y] perfecto; y [viceversa,] si no puede hacerlo cuando su estado es maduro, es incapaz de ello cuando éste es imperfecto. Viéndolo ser [primero] un niño, luego un joven, luego un hombre adulto y finalmente un anciano, sabemos que él no se ha trasladado por sí mismo desde el estado de la juventud hasta el estado adulto, pues aunque él trate de librarse de la vejez y de regresar a su juventud, no puede hacerlo. Lo que hemos dicho muestra que no es él quien se traslada por sí mismo de un estado al otro, sino que hay alguien que lo traslada de estado en estado y que dirige tales cambios, ya que no es posible el cambio de un estado a otro sin [que] un causante (nāqil) y un dirigente [lo efectúe]" (Kitāb al-Luma I, I, § 3). En otros términos, la evolución de un ser humano de un estado a otro (semen-embrión-feto-carne, huesos y sangre) exige la intervención de otro agente que haya dispuesto ese orden. Este argumento apoya la doctrina islámica según la cual Allāh es hacedor y ordenador del mundo. Por tanto, no puede concebirse, según al-Ash arī, la preexistencia eterna del semen: de ser así, el semen no sería capaz de mutar por sí mismo. Es preciso, pues, postular una causa distinta del semen que permita la mutación y el cambio: dicha causa, será el Creador (al-Bāri'), un agente completamente diferente de las criaturas, eterno, increado y, además, uno. Sobra decir que los filósofos árabes influidos por Aristóteles, especialmente Averroes, ven claramente que no hace falta apelar a la acción directa de un creador para dar razón de los procesos naturales. 
[divina], debe abarcar todo aquello que puede realmente conocerse. [...] Allāh, ensalzado sea, es el Creador de todo cuanto comienza a existir, y [es evidente asimismo que] Él no puede crear aquello que Él no quiere; el propio Allāh, ensalzado sea, ha dicho [por medio de Su enviado]: "[Él,] que siempre hace lo que quiere". (Kitāb al-Lumac III, XVI, § 49)

La voluntad divina abarca cuanto existe y, en este sentido, todo cuanto acontece en el mundo está sometido a los deseos divinos. Dios es el único agente. En realidad, la intención de Al-Ash ${ }^{\circ}$ arī en varios de sus escritos teológicos era encontrar una manera de reconciliar la soberanía divina con las acciones que se dan en el mundo y, especialmente, con la responsabilidad moral. Sin embargo, su alternativa, la denominada doctrina $k a s b$, es a mi juicio fallida dado que, en esencia, lo que sostiene es que Dios desea y crea todos los actos, y otros ejecutores son sus receptores:

Los actos han de tener necesariamente un agente que los cree, ya que no pueden prescindir de éste. Y si el agente que crea el acto tal como es no puede ser el cuerpo, tiene que serlo Allāh, ensalzado sea. Pero el acto no necesita de alguien que lo adquiera tal como es en el mismo sentido en que [decimos que] necesita de un agente que lo cree tal como es, de modo que si se trata de una adquisición (kasb) Allāh debe ser su adquisidor. ${ }^{4}$ (Kitāb al-Luma` V, XXVII, § 88)

En el caso de los actos humanos es evidente que ha habido un adquisidor que no es Dios: los humanos somos presuntamente responsables de nuestras acciones. No obstante, en la doctrina kasb Dios es el único agente libre (ha creado libre y voluntariamente el mundo, incluyendo las acciones que acontecen en él), y no sólo eso: cualquier causalidad está determinada por Él, incluyendo nuestro libre albedrío. En resumidas cuentas, todo está determinado por la voluntad divina y no existe ninguna otra causalidad que no sea la divina. Dios es la causa eficiente de cuanto existe. Sin embargo, lejos de afirmar que los seres humanos son responsables de sus acciones, la radicalidad de este planteamiento

\footnotetext{
${ }^{4}$ Este pasaje podría resultar sumamente ambiguo. ¿Cómo puede ser que Dios sea el adquisidor siendo el creador? ¿No se supone que la doctrina kasb sostiene que Dios es creador de los actos pero los adquisidores son los ejecutores? Todo indica, como señala Richard J. McCarthy (al-Ash ${ }^{c}$ arī 1953, p. 57) en su traducción del Kitāb al-Luma a la lengua inglesa, que hay en este pasaje un problema terminológico. Es obvio que en el caso de las acciones humanas, explica McCarthy, Dios no puede ser sujeto de tales adquisiciones. Si se revisa el capítulo quinto del Kitāb al-Luma se puede entender que, en realidad, los adquisidores o ejecutores son los humanos.
} 
parece negar esta posibilidad y en él Dios aparece como el único agente libre. ${ }^{5}$ Más adelante, cuando se expliquen las características que, según al-Ghazālī, debe tener un agente libre, será más claro por qué solamente Dios puede serlo.

En contraste con el planteamiento anterior, todo indica que en la doctrina islámica la omnipotencia divina ha permitido que los seres humanos sean responsables de sus actos y por esto ha dispuesto para ellos el premio o el castigo. ${ }^{6}$ En este sentido, el mal moral también provendría de Dios. No obstante, ello no supone un problema para los asharíes: el musulmán asiente y confía en que, a pesar de que sus actos son adquiridos, Dios no impondrá ninguna acción que pueda resultar una carga excesiva para los creyentes:

Allāh, ensalzado sea, no impone nada a nadie que pueda resultarle una carga excesivamente severa, como por ejemplo, expulsar [sin más] del alma aquellos pensamientos que [nos] invitan al mal, pues Allāh puede disculpar éstos y ser generoso con los musulmanes acerca de la desobediencia a la que [en ocasiones] se ven llevados [los hombres] caso de que finalmente no la cometan tras resultarles ella una carga. Luego el significado de Sus palabras: "Allāh no pide a nadie más allá de sus posibilidades" es: sólo nos

${ }^{5}$ Insisto en que, para los asharíes, Dios es un "agente libre". En la tercera discusión del Tahāfut al-Ghazālì arremete en contra de los filósofos que han postulado un modelo emanacionista en el cual Dios no crea el mundo libre y voluntariamente, sino que se apuesta por el necesitarismo divino.

${ }^{6}$ En una religión revelada que contempla el castigo y, por lo tanto, la existencia del mal, emerge enseguida la siguiente cuestión: si Dios es causa única de cuanto existe, ¿es también causa del mal? O dicho en otros términos, ¿permite que los agentes actúen mal? Y todavía más: ¿permite que haya infieles? Un pasaje relevante a este respecto aparece en el Kitāb al-Luma" de al-Ash'arī: "si hubiera en el universo algo no querido por Allāh, ensalzado sea, sería algo cuya existencia Él rechazaría. [¿]Habría que concluir entonces que las faltas [humanas] existen con independencia de que Allāh las quiera o no[?] iHe aquí una descripción apropiada [en todo caso] para alguien débil y heterónomo! Pero nuestro Señor está [sin duda muy] por encima de esto!" (Kitāb al-Luma III, XVI, § 53). En otras palabras, todo indica que al-Ash'arī se inclina a pensar que Dios también desea la existencia de los actos malévolos y la de los infieles. La existencia del mal no podría ser ajena a Dios porque ello supondría un "punto ciego" para Él y ello supondría un límite para su omnipotencia. Es cierto, entonces, que Dios aprueba y reprueba actos, premia y castiga, y ha revelado su Ley para que los fieles conozcan los actos que han de procurar y los que deben evitar. La presencia del pecado, del mal y de que se den los actos reprobables es algo que nos excede a nosotros, mas no a Él. Por ello, el musulmán está obligado a asentir y a confiar en la providencia: Dios conoce la lógica de los acontecimientos; los humanos no y, por ello, se someten a la voluntad de Dios. 
pide lo que Él hace que sea posible para nosotros. Pues lo que Allāh, ensalzado sea, ordena hacer a Sus criaturas no es excesivamente difícil para ellas, y ellas no son incapaces de hacerlo. Según algunos de entre nosotros, la frase "Allāh no pide a nadie más allá de sus posibilidades" significa [en realidad]: sólo nos pide lo que legalmente podemos hacer. (Kitāb al-Luma" VI, LIV, § 149)

El determinismo divino en la teología asharí está respaldado por una concepción específica de la causalidad que debe entenderse a partir de su modelo cosmológico. Los asharíes construyen su cosmología desde un planteamiento atomista muy similar al atomismo helénico ${ }^{7}$ que les permitirá sostener la necesidad de un mecanicismo determinista. Dicho rápidamente, para los asharíes, todos los cuerpos materiales están formados por átomos ( $a \breve{g} z \bar{a})$ que, reunidos, dan lugar a la variedad de cuerpos que conforman la realidad. Los átomos existen separados entre sí por el vacío (halāa) y cuando entran en contacto entre sí, conforman un cuerpo. Éste no será sino una red de átomos que son distintos entre sí, que cambian radicalmente (es decir, se desintegran y se recrean constantemente). Este proceso es posible porque Dios crea y renueva libre y permanentemente sin que Él esté sujeto a leyes físicas y ni siquiera metafísicas: Dios es omnipotente. Recurrir a una filosofía de la naturaleza atomista es una alternativa idónea para defender la omnipotencia divina por las siguientes razones:

a) Con esta clase de atomización de la naturaleza se consigue eliminar la noción aristotélica de causalidad natural. En efecto, si la naturaleza tiene una estructura atomizada, todos los cambios físicos que puedan acontecer se explican desde una simple conexión de átomos y no hace falta recurrir a un modelo causa-efecto;

b) Si se elimina el modelo causa-efecto y se transmuta por una simple conexión, entonces se enfatiza la discontinuidad de la naturaleza, en vez de acentuar la continuidad de los fenómenos naturales;

c) Si la naturaleza es discontinua, no se rige por ninguna causa determinada y, finalmente, estamos en condiciones de comprender

${ }^{7}$ Un trabajo relevante sobre la influencia del atomismo en los círculos teológicos islámicos se encuentra en el clásico y controvertido trabajo de Majid Fakhry (1958, pp. 33-55). Se trata de uno de los primeros trabajos que motivó los debates sobre el ocasionalismo islámico. 
que el mundo no se rige por una causalidad intrínseca, sino que depende absolutamente de un artífice externo, a saber, Dios.

Si la naturaleza está atomizada y es discontinua, ello significa que está pereciendo a cada momento. Por ello, los asharíes sostendrán que, si bien Dios ha creado el mundo, a la creación $(h \bar{a} l q)$ sigue la disolución

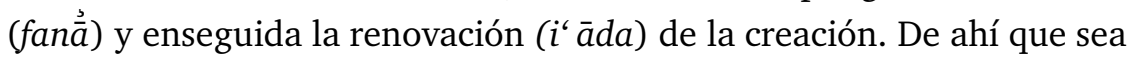
necesario postular un artífice externo cuya actividad sea la renovación constante del mundo. ${ }^{8}$ Esta postura es absolutamente compatible con lo que leemos en Corán 30:27: "Es Él Quien inicia la creación y, luego, la repite. Es cosa fácil para Él." Dios es la causa de que el mundo no perezca porque su voluntad divina actúa permanentemente en él. En un mundo discontinuo no existe la posibilidad, como decíamos ya, de explicar los fenómenos desde un modelo causal natural. En otras palabras, no hay causalidad fuera de la divina, no hay siquiera leyes que rijan la naturaleza y, por lo tanto, la filosofía de la naturaleza de los asharíes será incompatible con la aristotélica. Para los asharíes, en realidad no existe la causalidad natural, sino que nuestra mente percibe los fenómenos naturales de manera continua y les atribuye causalidad. No obstante, si no hay causalidad intrínseca a los fenómenos naturales, estamos en condiciones de defender lo que a tono con los asharíes alGhazālī defiende en la discusión decimoséptima del Tahāfut, a saber, que Dios puede interferir en los fenómenos naturales si así lo desea. ${ }^{9}$

Existe, pues, una diferencia significativa entre el planteamiento de la causalidad natural defendida por los filósofos y la causalidad divina defendida por los teólogos asharíes. En la discusión decimoséptima del Tahāfut esta diferencia es clara: ante un fenómeno físico como la combustión de un objeto por el fuego, los filósofos asumirán que el fuego es la causa eficiente de la combustión. No obstante, al-Ghazālī defenderá que, en realidad, el fuego es una entidad inorgánica incapaz de ejercer actividad alguna por sí mismo: en realidad la causa eficiente de la combustión sería Dios y no el fuego. Se lee en la discusión decimoséptima:

Para nosotros [los teólogos] no es necesario (darūrī) que haya un enlace (iqtirān) entre lo que se considera causa y lo que se considera efecto. ${ }^{10}$

${ }^{8}$ Una estupenda explicación de este proceso puede leerse en el trabajo de Dominik Perler y Ulrich Rudolph (2000, pp. 28-56).

${ }^{9}$ Por supuesto, se discute todavía si al-Ghazālī niega la causalidad de la misma manera en que lo hacen los asharíes. A este respecto, véanse artículos como el de L.E. Goodman (1978), el de I. Alon (1980), o el de B. Abrahamov (1988).

${ }^{10}$ No es necesario que haya siempre un enlace entre causa y efecto. Podría enten- 
Nada tiene que ver una con otro. [...] De la existencia de la [causa] no se sigue la existencia del [efecto], ni de la privación de la primera la privación del segundo. Por ejemplo, calmar la sed no se sigue de la existencia del beber, ni el hartarse del comer, ni el quemarse del contacto con el fuego; tampoco [se sigue] la luz del nacimiento del sol; ni la muerte de la decapitación, ni la curación de la ingestión del remedio, ni la purga del vientre de [la ingestión] de un purgante. [...] El enlace entre ambas cosas [la causa y el efecto] en los ejemplos anteriores obedece a una decisión previa de Dios que las ha creado simultáneamente; pero no es que tal enlace sea necesario e indefectible. [...] Los filósofos, por el contrario, niegan tal posibilidad pretendiendo que todo eso es absurdo. (Tahāfut XVII, § 1, 5)

En esta discusión decimoséptima, discutida recurrentemente por los especialistas en filosofía árabe-islámica, encontramos un determinismo radical, y prácticamente una posición ocasionalista. ${ }^{11}$ Al-Ghazālī está defendiendo que el fuego no es la causa de que algo se queme, sino que ello obedece a una disposición divina, con lo cual, el fuego no es la causa de la combustión, sino que ésta se da con ocasión del fuego, no por el fuego en sí mismo. Dios es, en este escenario, el único creador de todo movimiento y accidente que se da en el mundo. No existen, como defenderían los filósofos, causas segundas. ${ }^{12}$ Todo está dominado por una única voluntad y ésta es la única responsable de que pueda darse alguna conexión entre unos acontecimientos y otros. A mi juicio, el de al-Ghazālī y los asharíes es un ocasionalismo naturalista. Planteemos

derse, entonces, que habitualmente ese enlace existe pero no de manera necesaria, ya que, si Dios lo desea, puede interferir en él. Este matiz podría sugerir que alGhazālī no niega la causalidad natural. No descarto esta opción; sin embargo, no termina de convencerme dado que al-Ghazālī piensa, finalmente, como se ve hacia el final de este pasaje, que de existir algún enlace causa-efecto, éste provendría de una decisión divina previa.

${ }^{11}$ A mi juicio, al menos en el orden de la naturaleza, la postura de al-Ghazālī es ocasionalista; sin embargo, se trata de un tema muy debatido. No descarto que en algún momento podría variar mi postura a este respecto. Mientras tanto, como apunta Thérèse-Anne Druart, la discusión continúa: Goodman, Alon, Bahlul, Giacaman, Abrahamov, Frank, Marmura y, obviamente, la propia Druart, discuten el sentido de causalidad en al-Ghazālī, la posibilidad de que acepte la existencia de causas segundas y no solamente la divina, hasta qué punto es al-Ghazālī un asharí, etc. (véase Druart 2006). Hasta el momento, coincido con Marmura en que al-Ghazālī postula una única causalidad, la divina (véase Marmura 2002, pp. 102103; y 1981). Por tanto, como mostraré, en este sentido su posición con respecto a las acciones humanas es determinista.

${ }^{12}$ Véase la nota 10. El problema, a mi juicio, es que aunque al-Ghazālī admitiese las causas segundas, nada impide, como menciono hacia el final, que éstas también dependan de la voluntad divina. 
el problema ahora desde la presunta responsabilidad de los agentes humanos y no desde los procesos de la naturaleza. Estos últimos, como se ha visto, acontecen con ocasión de la voluntad divina; pero, ¿qué pasa con las acciones que provienen de un agente presuntamente libre y responsable como el ser humano?

\section{Al-Ghazālì y el problema de la acción libre}

En la tercera discusión del Tahâfut al-Ghazālī explica que un agente libre debe reunir una serie de características para que pueda considerarse propiamente agente:

a) El agente es el productor de una acción;

b) Él desea y decide sobre esa acción;

c) Lo hace porque es capaz de deliberar y elegir libremente;

d) Conoce tanto su acción particular como el objeto que ha producido libremente con esa acción (cfr. Tahāfut III, § 4, 5).

Con estas características está garantizado que Dios es un agente libre. Y, en efecto, en la tradición musulmana ello significa que Él ha creado el mundo por voluntad libre. Si el mundo es su acción, Él decide libremente sobre él. Ésta es la razón por la que, como veíamos antes al revisar la discusión decimoséptima, Dios puede interferir en el orden natural y hacer que el fuego no queme: Dios puede todo. Dios está por encima de toda ley física, lógica y metafísica. De hecho, toda ley física, lógica y metafísica está sometida a Él. Ahora bien, si Dios es el único agente, ¿habría algún margen para otro agente libre? ¿Es posible sostener el libre albedrío y la responsabilidad moral? Si un agente $A$ entiende que él no es responsable de sus acciones, sino que éstas son adquiridas (kasb), parecería que no es posible hablar ni de libre albedrío ni de responsabilidad moral e incluso ni siquiera es posible considerarlo un agente. Dios estaría controlando las acciones del mundo y las de los agentes humanos. Por lo tanto, la voluntad divina es incompatible con el libre albedrío de los seres humanos.

Mucho se ha discutido si el punto de vista expresado en esta tercera discusión es la postura definitiva de al-Ghazālī. Dado que la finalidad del Tahâfut es cuestionar algunas de las conclusiones a las que han llegado los filósofos, posiblemente no sea el texto adecuado para concluir que al-Ghazālī es definitivamente partidario del determinismo de las acciones humanas. Por ello, con la intención de mostrar que al menos 
en algunos de sus escritos en cierto modo lo es, recurro a un pasaje de uno de sus escritos de madurez. En La vivificación de las ciencias de la religión (Ihyā' 'ulūm al-dīn), ${ }^{13}$ un tratado en el que sigue existiendo la influencia de la teología asharí, uno de los tantos problemas filosóficos que se plantean es, precisamente, el del libre albedrío, un tema que, según el propio al-Ghazālī, ha sido un motivo de discusión y que, al parecer, podría resolverse satisfactoriamente recurriendo a ciertas doctrinas asharíes y a algunos planteamientos matizados y reinterpretados de la filosofía avicenista. Todo indica que, en este escrito de madurez, al-Ghazālì es mucho más condescendiente con Avicena que en el Tahāfut. En La vivificación de las ciencias de la religión intenta reordenar los argumentos asharíes y avicenistas con la finalidad de dar cabida al libre albedrío. No obstante, a mi juicio, tampoco en este tratado logra escapar del determinismo. Tengamos en consideración el siguiente planteamiento sugerido por Marmura:

a) El criterio básico de acción para todo musulmán es evitar el vicio y el pecado, y optar por una vida buena que lo conduzca a la salvación.

b) Al-Ghazālī encuentra que, ante (a), pueden existir dos posiciones encontradas: o interpretar los preceptos religiosos de manera determinista (al-jabriyya) o abrir un espacio para la voluntad libre (qadariyya). Marmura explica que al-Ghazālī evalúa una tercera opción, a saber, la que admite que las acciones humanas están en parte determinadas por Dios, pero también el agente decide libremente sobre ellas (cfr. Marmura 2002, pp. 102-103);

c) He aquí la cuestión más compleja: existe la voluntad libre, pero los actos han sido creados por Dios para esa voluntad libre. Marmura hace notar que éste es el mismo planteamiento que aparece, precisamente, en la doctrina kasb de los asharíes (cfr. Marmura 2002, p. 104).

Me parece claro que al-Ghazālī sigue la línea asharí. Su postura se ajusta, además, a una de las aseveraciones más controvertidas del Corán: "Allah os ha creado a vosotros y a lo que hacéis" (Corán 37:96). Me detengo en un pasaje clave de La vivificación de las ciencias de la religión que, a mi juicio, respalda esta cita coránica:

${ }^{13}$ La vivificación de las ciencias de la religión es un escrito en el que al-Ghazālī se consagra como un pensador religioso y simpatizante del sufismo. Por lo tanto, los límites de la razón frente a las creencias religiosas es un tema recurrente en ese trabajo.

Diánoia, vol. LIV, no. 63 (noviembre 2009). 
Si te preguntas si el agente es libre de actuar o contenerse, respondemos que sí; y esto es así, porque ello no supone contradicción alguna cuando decimos que todo proviene de la creación de Dios, Él sea alabado. Dado que Dios ha creado la mano sana, la comida sabrosa y en el estómago el apetito por la comida, [por lo tanto,] ha creado en el corazón el conocimiento de que esa comida calma el apetito; Él creó los pensamientos en conflicto como [cuando] un alimento es dañino aunque calme el apetito y, si antes de haberlo tomado hay o no algún impedimento que haga posible el tomarlo, creando después el conocimiento de que no hay impedimento. Cuando todas estas causas se combinan, el impulso de la voluntad resulta decisivo; la decisión de la voluntad tras la indecisión de los pensamientos en conflicto y después de que la acción del apetito sobre la comida ha ocurrido, se llama "elección" y ocurre inevitablemente cuando las causas se han completado. (Ihȳà' 'ulüm al-dìn IV, 5) ${ }^{14}$

Este pasaje ofrece varias consideraciones relevantes. Comienzo por la parte final: de acuerdo con al-Ghazālī existe la "elección libre" cuando se conjugan una serie de causas que van desde la deliberación hasta la acción concreta. Sin embargo, a mi juicio, en este modelo podemos ver que aunque un agente $X$ haya deliberado y conozca la conclusión de su deliberación, y ello le haga pensar que ha actuado libremente, en realidad sus acciones han sido controladas a través de una red causal establecida por Dios. En otros términos, la conjunción de causas es ocasionada por Dios: Él ha dispuesto que existan el alimento y el apetito; ha dispuesto también que existan algunos alimentos dañinos y que, ante ello, el agente racional pueda hacer uso de su capacidad deliberativa. Ahora bien, la alusión a esta capacidad deliberativa no significa que el agente decida por sí mismo. Más bien, los agentes deliberan en un sentido muy restringido pues Dios ha permitido que se dé la conjunción precisa de las causas para que la elección establecida previamente por Él pueda darse. En pocas palabras, la elección libre no es una facultad humana, sino una disposición divina. ${ }^{15}$ De modo que un agente podría pensar que ha elegido libremente sobre sus actos cuando, en realidad, Dios dispuso que en determinado momento se alinearan un conjunto de causas que dieron lugar a determinado curso de los acontecimientos, se trate de acciones aprobadas o reprobadas. Así es como se defiende,

\footnotetext{
${ }^{14}$ Marmura también alude a este pasaje. He elaborado mi propia traducción del texto árabe establecido por Hafiz Iraqi y que se encuentra disponible en <http:// www.ghazali.org/>.

${ }^{15}$ En el capítulo séptimo del próximo libro de Frank Griffel (2009) se estudia a fondo esta cuestión. He consultado el manuscrito que el autor ha tenido la gentileza de proporcionarme.
} 
pues, que supuestamente es posible armonizar la voluntad divina con el libre albedrío. Creo que la alternativa de al-Ghazālī en La vivificación de las ciencias de la religión no es otra cosa que una versión moderada de la doctrina kasb.

Al-Ghazālì plantea que el ser humano es agente responsable de sus acciones no porque él sea un agente libre, sino porque Dios ha dispuesto la red causal para que el acto libre se concrete. Los asharíes distinguen la acción divina, es decir, una acción creadora, de la acción humana, es decir, una acción adquirida. Esta postura no rechaza que Dios sea responsable de las acciones humanas (de no ser así, la omnipotencia divina sería limitada). Lo que sucede es que Dios ha otorgado a los seres humanos una potencia operativa a través de la cual cada uno puede apropiarse o no, de las obras que Dios como único agente ha dispuesto para él.

\section{Averroes y el Tahāfut al-Tahāfut}

Conocemos ya la aproximación de al-Ghazālī al problema del determinismo en dos escritos, el Tahâfut y la Ihyā' 'ulūm. La refutación al determinismo de al-Ghazālī y los asharíes la encontramos en Averroes, en su Tahāfut al Tahāfut (Incoherencia de la incoherencia). ${ }^{16}$ En él construye una serie de contraargumentos que responden a las críticas de al-Ghazālī a la filosofía. Con orden y cautela, el cordobés explica cuáles son los argumentos ghazalianos e intenta responderlos. Los contraargumentos averroístas fungen en buena medida como una puntualización del aristotelismo y corrigen tanto los pareceres de al-Ghazālī como el de los filósofos neoplatónicos con los que el teólogo discute: al-Fārābī y Avicena.

No es el lugar para elaborar un análisis exhaustivo de todos los contraargumentos averroístas. Sin embargo, revisaré algunos pasajes, especialmente de la respuesta averroísta a la tercera discusión del Tahāfut al-falāsifa. Ahí se reúnen, a mi juicio, las principales objeciones al determinismo de al-Ghazālī. En Tahāfut 158, Averroes afirma: "la doctrina asharí no reconoce una voluntad libre en los hombres ni [acepta] que tengan poder para actuar en la realidad". Antes, en Tahäfut 147-149, Averroes ha enunciado las tres primeras objeciones de al-Ghazālī en contra de los filósofos:

\footnotetext{
${ }^{16}$ Viene al caso recordar que las posiciones filosóficas definitivas de Averroes no se encuentran en el Tahāfut al Tahāfut. Él mismo nos advierte que en este trabajo presenta un ejercicio dialéctico con la finalidad de enmendar algunas imprecisiones filosóficas de al-Ghazālī.
} 
(1) Un agente debe desear y conocer aquello que desea; los filósofos piensan que Dios no desea y que lo que de él procede se da por necesidad;

(2) Los filósofos afirman que el mundo es eterno y pierden de vista que, si Dios actúa, los actos implican producción;

(3) Los filósofos afirman que Dios es Uno y que la pluralidad del mundo no puede explicarse de la unicidad pues, dicen, de la unicidad solamente puede seguirse unicidad.

Nos interesa el contraargumento de (1). Averroes explica que (1) no es evidente y supone que se ha probado que de lo empírico puede inferirse lo divino. Además, en la crítica ghazaliana no se distinguen las dos clases de agentes que existen: i) los agentes naturales y ii) los agentes voluntarios. Los primeros son aquellos que solamente pueden actuar de una manera. En este sentido, están naturalmente determinados. ${ }^{17}$ En cambio, los agentes voluntarios son aquellos que no están determinados a actuar de una sola manera, sino que pueden elegir entre contrarios porque están dotados de conocimiento y deliberación. No obstante, no parece un argumento eficaz en contra de lo que al-Ghazālī ha pensado, pues aun en el caso del agente voluntario los actos serían adquiridos.

En otras palabras, como mencionaba en el apartado anterior, en cierta manera al-Ghazālì estaría de acuerdo con que existen agentes voluntarios, pero propondría que los actos de un agente $A$ son en realidad adquiridos, y si elige $p$ en vez de $q$, no es que por su conocimiento y capacidad deliberativa esté en condiciones de elegir $p$; más bien, su elección de $p$ es un acto adquirido; Dios permite que elija $p$ y, en este sentido, la intervención del agente humano es muy limitada. Ahora bien, Dios permite que, a través de la facultad cognoscitiva, los seres humanos se percaten de que algunos actos son necesarios y otros, los "libres", son adquiridos. Por ello, la mejor alternativa, aún racional, es la sumisión a la voluntad divina.

A este respecto, Averroes recurre a los siguientes contraargumentos:

(a) Primero, en Tahāfut 220, 5-10, respondiendo precisamente a la tercera cuestión, Averroes alega que negar la causalidad natural y atribuir toda acción a la voluntad divina implica la negación de

${ }^{17}$ De ahí que la filosofía de la naturaleza averroísta admita una interpretación determinista. Ésta es una cuestión que habría que discutir a fondo y que Catarina Belo desarrolla de manera magistral en su libro Chance and Determinism in Avicenna and Averroes (2007). 
la naturaleza de las cosas. En otras palabras, podemos conocer la naturaleza a través de sus operaciones; por lo tanto, si éstas son suprimidas, la naturaleza se reduce prácticamente a la nada. Siguiendo a los asharíes, dice Averroes, si se niegan los actos que proceden de la naturaleza y si, todavía más, se niega que los seres vivientes que vemos en el mundo natural son capaces de actuar, entonces habría que concluir que "en el mundo empírico no hay vida del todo y, dado que podemos inferir que hay vida a través de los actos de los seres del mundo empírico, sería interesante saber cómo obtienen [los asharíes] las conclusiones que presentan" (Tahāfut 220, 10). Averroes se pregunta, pues, ¿cómo concluir que Dios actúa sobre la naturaleza sin que exista una distinción precisa entre la operación divina y la operación natural?;

(b) En consonancia con (a), Averroes sostendrá que es necesario distinguir entre la causalidad divina y las causas segundas que, en contraste, no son posibles en el caso de los teólogos. Averroes defiende la existencia de causas segundas y, a diferencia de los asharíes, defiende el nexo necesario entre causa y efecto: no puede darse ningún efecto si no hay causa natural. Averroes defiende la existencia de las causas segundas explicando que éstas pueden ser tan diversas como los seres;

(c) Frente al atomismo asharí, Averroes defiende el hilemorfismo aristotélico y, con ello, la continuidad de la naturaleza. Si hay continuidad, es posible defender la causalidad natural. Averroes afirma que la voluntad divina sí actúa en la naturaleza, pero no del modo en que pensaron los asharíes. En Tahāfut 152, una vez más respondiendo a la tercera discusión, Dios es la causa primera de los acontecimientos, pero no de manera directa. Averroes alega que debe distinguirse entre el mundo (que ha recibido la existencia de Dios) y Dios mismo: la naturaleza es algo separado de la voluntad divina y se rige por leyes naturales. Dios es causa en tanto que todos los acontecimientos naturales provienen de Su acción eterna. En este sentido, el mundo, tal como sostuvo Aristóteles, es eterno y necesario. Pero soslayo esta discusión que tendría demasiadas aristas y nos enfrentaría a una serie de problemas que desviarían ligeramente el planteamiento de mi trabajo. De entrada, habría que discutir si Averroes cree en la creación ex nihilo o no y, en efecto, paradójicamente no cree en 
ella. Basta con anotar, pues, que Averroes reivindica la causalidad y distingue entre la causalidad primera y eterna de Dios de las causas segundas que, según el cordobés, son evidentes e irrefutables si ponemos atención a nuestra experiencia física. Por ello, más adelante, en la respuesta a la discusión número diez, escribe:

La opinión que niega las causas de un modo total es contraria a la naturaleza humana, y la que las niega en el mundo cierra el camino para afirmar la existencia de una causa eficiente en el mundo invisible, pues no se pueden alcanzar las causas invisibles sino partiendo de las causas visibles. Así pues, los asharíes carecen de camino alguno para conocer a Dios Altísimo, en tanto que se niegan a reconocer que no hay efecto sin causa. Siendo así, la creencia unánime de los musulmanes acerca de que no existe otro creador que Dios Glorioso no puede significar la negación absoluta de la causa eficiente en el mundo visible, pues de la existencia de ésta aquí abajo deducimos la del agente en el mundo invisible. (Tahāfut 416-417)

Ahora bien, reivindicada la causalidad natural, pasemos a la problemática del agente libre. Es aquí donde viene al caso evaluar si Averroes encuentra un argumento más consistente para defender una causalidad libre. Averroes sostendrá que:

a) El término agente ( $\left.f a{ }^{\prime} i l\right)$ no se dice de la misma manera de Dios que de las demás causas:

Dios no es un agente como los demás agentes que son sensibles, voluntarios o involuntarios. [Él] es más bien el agente de las causas, es lo que conduce al universo de la no existencia a la existencia y lo conserva. Es evidente, entonces, que su acto es más glorioso y perfecto que [los actos] ejecutados por los agentes sensibles (Tahäfut 151, 5);

b) En consonancia con (a), existe, pues, una diferencia entre los agentes naturales y el agente "libre". En este último caso, los actos proceden del entendimiento y la voluntad. De modo que en el primer caso hay causalidad natural (es decir, aquella, según Averroes, en la que opera necesariamente un solo tipo de acto y donde hay incluso una acción propia, a saber, la actualización de las potencias naturales) y, en el segundo, "causalidad libre" ya que, como se alega en Tahäfut 158, los agentes voluntarios son capaces de actuar contrariamente. En otros términos, si un agente puede elegir entre los contrarios, entonces estamos hablando 
de un agente libre y responsable. Habría que distinguir, pues, entre una causalidad unidireccional (el ojo fue hecho para ver y no tiene otra función) y una multidireccional que sería la definitoria del agente voluntario, libre y responsable de sus actos.

c) Por la distinción aducida en (b), a saber, la de un agente natural y un agente voluntario, habría que distinguir, siguiendo a Averroes, la voluntad divina de la voluntad humana. En Tahäfut 160, Averroes afirma que no pueden ser la misma la voluntad de Dios y la humana. Dios es causa de las causas y, dada su perfección, sus acciones son necesarias; ${ }^{18}$ en cambio, la voluntad humana se sitúa en el terreno de la posibilidad y no de la necesidad:

aquel que da a los seres separados su fin es el mismo que les confiere su existencia, pues en este tipo de seres la forma y el fin son idénticos. Y así, aquel que da el fin es quien da la forma; luego, el que da la forma es el agente. Así pues, parece que el Principio Primero es el principio de todos estos principios en cuanto que es su agente, su forma y sin fin. En cuanto a su relación con los seres sensibles, en cuanto que es Él quien les da su unidad y que ésta constituye un lazo, Él será principio en cuanto que es agente, forma y fin. Todos buscan, pues, su fin y se mueven hacia él, cada uno con un movimiento propio de su razón de ser, natural para todos los seres, voluntario para el hombre; y por esto el hombre es, entre ellos, el único responsable y el único confidente. (Tahāfut 232, 10)

Hasta aquí, parecería que Averroes nos presenta una crítica consistente contra el determinismo asharí, representado por al-Ghazālī. No obstante, lo que vemos es un conjunto de argumentos que precisan ciertos usos de la terminología filosófica utilizada por al-Ghazālī, pero no deshacen frontalmente el problema del determinismo. Así, si bien es cierto que Averroes tiene razón en que habría que distinguir entre la causalidad natural y la causalidad divina, los agentes naturales y los agentes voluntarios, la voluntad divina y la humana, si bien habría que afinar en qué sentido Dios es causa eficiente del mundo, en realidad, ninguno de esos argumentos desarma frontalmente el determinismo divino de los asharíes.

\footnotetext{
${ }^{18}$ He aquí un contraste más entre al-Ghazālī y Averroes. Para el primero, Dios es el único agente libre que existe; en cambio, para Averroes Dios no es libre porque en él no existe la posibilidad. Siguiendo a Aristóteles, Averroes identifica lo necesario con lo eterno y defiende recurrentemente que en lo necesario no hay manera de que pueda infiltrarse la posibilidad (véase Averroes 1991, cuestiones quinta y novena).
} 
Hasta donde veo, nada impide que las causas segundas se susciten también bajo el consentimiento de la voluntad divina, así como tampoco existe impedimento alguno, como he insistido, para que el agente voluntario que elige aparentemente entre contrarios esté determinado a elegir $p$ en vez de $q$. En este sentido, me parece que el problema del determinismo divino, tal como está planteado en los asharíes y en alGhazālīi, sigue vigente y, sobre todo, que plantear que la elección entre dos o más posibilidades es una resolución efectiva es algo cuestionable al menos en la mentalidad teológica de un asharí.

\section{BIBLIOGRAFÍA}

Abrahamov, B., 1988, "Al-Ghazālì's Theory of Causality", Studia Islamica, no. 67 , pp. 75-98.

Al-Ash arī, 2006, Contra heterodoxos (al-Luma') o lo que deben creer los musulmanes, trad. Carlos A. Segovia, Biblioteca Nueva, Madrid.

—, 1953, The Theology of Al-Ash arī (Kitāb al-Luma'), trad. Richard C. McCarthy, Imprimérie Catholique, Beirut.

Al-Ghazālī, s/f, Ihyā' 'ulūm al-dīn [La vivificación de las ciencias de la religión], texto establecido por Hafiz Iraqi, disponible en línea en <http://www. ghazali.org/>; consultado el 27 de abril de 2008.

— 2000, The Incoherence of the Philosophers, edición árabe-inglés, trad. M. Marmura, Brigham Young University Press, Provo, Utah.

_ 1989, Confesiones: El Salvador del error, trad. Emilio Tornero, Alianza, Madrid.

Alon, I., 1980, "Al-Ghazālī on Causality", Journal of the American Oriental Society, vol. 100, no. 4, pp. 397-405.

Averroes, 1991, Questions in Physics, trad. H.T. Goldstein, Kluwer Academic Publishers, Holanda.

- 1987, The Incoherence of the Incoherence, trad. Simon van den Bergh, E.J.W. Gibb Memorial, Londres.

Belo, C., 2007, Chance and Determinism in Avicenna and Averroes, Brill, Leiden. Druart, T., 2006, "Al-Ghazālī's Conception of the Agent in the Tahāfut and the Iqtisāā: Are People Really Agents?", en James E. Montgomery (comp.), Arabic Theology, Arabic Philosophy. From the Many to the One: Essays in Celebration of Richard M. Frank, Uitgeverij Peeters en Departement Oosterse Studies, Lovaina, pp. 425-440.

Fakhry, Majid, 1958, Islamic Occasionalism and Its Critique by Averroes and Aquinas, George Allen and Unwin, Londres.

Frank, R.M., 1994, Al-Ghazālī and the Ash'arite School, Duke University Press, Durham/Londres.

__ 1992, "The Science of Kalām", Arabic Sciences and Philosophy, vol. 2, no. 1 , pp. 7-37. 
Goodman, L.E., 1978, "Did al-Ghazālī Deny Causality?", Studia Islamica, no. 47, pp. 83-120.

Griffel, Frank, 2009, Al-Ghazali's Philosophical Theology, Oxford University Press, Nueva York.

Ibn al-Nadìm, 1998, The Fihrist, trad. B. Dodge, Columbia University Press, Nueva York.

Kogan, B.S., 1985, Averroes and the Metaphysics of Causation, State University of New York Press, Nueva York.

Marmura, M.E., 2002, "Ghazālī and Ash'arism Revisited", Arabic Sciences and Philosophy, vol. 12, pp. 91-110.

— 1981 , "al-Ghazālī's Second Causal Theory in the 17th Discussion of the Tahăfut and the Iqtisāad", en Parviz Morewedge (comp.), Islamic Philosophy and Mysticism, Caravan, Nueva York, pp. 85-112.

Perler, Dominik y Ulrich Rudolph, 2000, Occasionalismus, Theorien der Kasualität im arabisch-islamischen und im europäischen Denken, Vandenhoeck und Ruprecht, Gotinga.

Rashid Bhat, A., 2006, "Free Will and Determinism: An Overview of Muslim Scholars' Perspective", Journal of Islamic Philosophy, vol. 2, pp. 7-24.

Recibido el 27 de junio de 2008; aceptado el 16 de junio de 2009. 